\title{
Una Aproximación integral a la presencia de las administraciones públicas en redes sociales ${ }^{1}$
}

\section{An integral approach to public administrations presence in social networks}

\section{Uma abordagem integral da presença das administrações públicas nas redes sociais}

\author{
Yolanda Agudo Arroyo \\ Profesora Contratada Doctora \\ (UNED) \\ https://orcid.org/0000-0002-6185-0899 \\ España \\ Javier Callejo Gallego \\ Catedrático Universidad \\ (UNED) \\ https://orcid.org/0000-0002-0856-5642 \\ España
}

Fecha de recepción: 8 de septiembre de 2018

Fecha de revisión: 13 de junio de 2019

Fecha de publicación: 1 de julio de 2019

Para citar este artículo: Agudo Arroyo, Y. y Callejo Gallego, J. (2019). Una Aproximación integral a la presencia de las administraciones públicas en redes sociales, Icono 14, 17 (2), 205-230. doi: 10.7195/ri14.v17i2.1237 


\section{Resumen}

El artículo se centra en la relación entre política y comunicación a partir de la irrupción de redes sociales online. La investigación desarrollada se pregunta por el alcance de esa relación en el contexto de las instituciones de la Administración Central del Estado español y el uso que hacen de las redes sociales Facebook y Twitter. Los objetivos que se planteaban eran conocer la audiencia producida, identificar la existencia de políticas públicas de comunicación concreta con respecto a estas redes, y establecer las principales dinámicas de la opinión pública, percepción de la interactividad y participación de los ciudadanos. El contexto de observación, eminentemente aplicado de la investigación, no impide señalar las hipótesis presentes, como la de la relevante extensión cuantitativa de la audiencia en tales redes sociales, y la de la inexistencia de una estrategia. Ahora bien, más allá de esta segunda hipótesis, el trabajo apunta a los potenciales peligros para la relación entre Estado y ciudadanos, y la posible inexistencia de estrategia. Para ello se ha diseñado una metodología de observación focalizada en registros de redes sociales online, complementada con entrevistas cualitativas a responsables de cuentas institucionales y grupos de discusión con audiencias. Se observa que la audiencia acumulada por estas instituciones en las redes sociales de referencia es superior a la de la mayor parte de los medios de comunicación en español. El tamaño de la audiencia de cada institución parece relacionado con la integración de las redes sociales en la política comunicativa de los organismos, la integración de los contenidos en la vida cotidiana y gustos de los receptores, y por la interactividad entre organismos y ciudadanos en las redes. Los discursos de receptores recogen un escaso sentimiento de democracia en la relación con las cuentas de social media de las instituciones.

Palabras clave: Redes sociales; Estado; Audiencia; Recepción

\section{Abstract}

This paper focuses on the relationship between politics and communication through social media. The empirical research asked about the significance of this relationship in the context of state agencies of Spanish Central Administration being the work in Facebook and Twitter the reference. 
Una Aproximación integral a la presencia de las administraciones públicas en redes... | 207 ARTÍCULOS DE INVESTIGACIÓN

The eminently applied observational context does has its hypothesis, such as the relevant quantitative extension of the audience in such social networks, such as the non-existence of a strategy. Beyond this second hypothesis, the work points to the potential dangers for the relationship between the State and citizens of its possibilityThe aims were to know the audience produced, to identify the existence of public policies of concrete communication with respect to these social media, and to establish the main dynamics of public opinion, perception of interactivity and citizens participation. In order to get those objectives, an online methodology of observation was designed, complemented with qualitative interviews to five community managers, and three focus groups. It is observed that the audience reached by the sum of all Facebook and Twitter accounts registered is greater than that of most Spanish media. The size of the audience of every state agency is conditioned by the social representation of the state agency, the integration of social media in the state agency communicative policy, the contents interaction whith receptors tastes and their daily life, and by the interactivity between organisms and citizens in the social media. The citizens discourses reflect a low sense of democracy in the relationship with the social media accounts of the state agencies.

Key Words: Social media; State; Audience; Reception

\section{Resumo}

0 artigo enfoca a relação entre política e comunicação a partir da irrupção das redes sociais online. A pesquisa realizada questiona sobre o alcance desta relação no contexto das instituições da Administração Central do Estado Espanhol e o uso que fazem das redes sociais Facebook e Twitter. Os objetivos foram conhecer o público produzido, identificar a existência de políticas públicas de comunicação concreta em relação a essas redes e estabelecer as principais dinâmicas da opinião pública, percepção de interatividade e participação dos cidadãos. 0 contexto de observação, pesquisa eminentemente aplicada, não impede as hipóteses atuais, como a extensão quantitativa relevante do público em tais redes sociais, e a falta de uma estratégia. Agora, além desta segunda hipótese, o trabalho aponta para os perigos potenciais para a relação entre o Estado e os cidadãos e a possivel falta de estratégia. Para 
tanto, foi elaborada uma metodologia de observação focada em registros de redes sociais on-line, complementada com entrevistas qualitativas com gerentes de contas institucionais e grupos de discussão com audiências. Observa-se que o público acumulado por essas instituições nas redes sociais de referência é superior ao da maioria dos meios de comunicação em espanhol. 0 tamanho do público de cada instituição parece relacionado à integração das redes sociais nas políticas comunicativas dos organismos, à integração dos conteúdos no cotidiano e aos gostos dos destinatários e à interatividade entre os organismos e os cidadãos na sociedade. redes. Os discursos dos destinatários refletem um baixo senso de democracia na relação com as contas de mídia social das instituições.

Palavras chave: Redes sociais; Estado; Audiência; Recepção

\section{Introducción}

El ataque del Presidente Trump al sistema de medios de comunicación desde escenarios públicos y en sus cuentas en social media, es característica de la actual legislatura norteamericana (Boczkowski y Papacharissi, 2018). Seguramente no se explican los ataques al sistema convencional de medios de comunicación (cabeceras de periódicos, cadenas televisivas, etc.), sin lo que se ha constituido en su canal de expresión para llegar a la sociedad, a sus ciudadanos, y a todo el mundo, incluyendo periodistas que recogen -sin capacidad de interacción- mensajes emitidos desde la cuenta presidencial, con más de 23 millones de seguidores (Twitter). La comunicación de la política, al menos de determinada política, no parece necesitar ya del sistema de medios como instrumento para llegar de inmediato a una audiencia masiva. Esto permite al poder político mantener a los medios a relativa distancia, aun cuando conservan un papel relevante en la producción de opinión pública (Hayes, 2018).

El Presidente español, Mariano Rajoy, en 2017 tenía más de millón y medio de seguidores en Twitter, siguiendo a poco más de 13.900 cuentas. Un número de seguidores superior el que tiene la mayor parte de los medios de comunicación en nuestro país. Como indica Webster (2014), una característica llamativa de los social media es su abundancia en las cifras. Por ello, conviene introducirse en ellas y en los contabilizados. 
Una Aproximación integral a la presencia de las administraciones públicas en redes... | 209 ARTÍCULOS DE INVESTIGACIÓN

El nuevo contexto de relación entre política y comunicación va más allá del campo de las audiencias, aun cuando aquí nos centramos en el mismo. Hasta ahora, se había asistido al fenómeno de millones de seguidores de instituciones mediáticas, pudiéndose recordar el temor que el potencial control de "mentes" despertó en amplio marco de pensadores sociales. Baste recordar la corriente "aguja hipodérmica".?

Hoy, el temor -en clave de fortaleza de la democracia- está detrás del potencial efecto de mensajes que, en lugar de una institución mediadora, dependen de una sola persona: político del país, famoso o deportista. Sin dejar a un lado, que los medios digitales recogen la identidad y actuación "digital" de sus usuarios (Susskind, 2018).

La dimensión comunicativa del poder político, en general, y especialmente el Estado moderno, adquiere una perspectiva distinta con la democratización de relaciones políticas y la extensión de canales y medios de comunicación. Aspectos que han de considerarse en paralelo. Puede definirse un estado avanzado de la democracia como el que tiene contrapeso en unos medios de comunicación, con línea editorial propia, necesarios para llegar políticamente a los ciudadanos. La irrupción de medios como las redes sociales online, posibilita una relación más directa entre política, gestores del Estado y ciudadanos (Ceron, 2015).

Nos preguntamos por el alcance que tiene esa posibilidad de relación directa en el contexto del Estado y la sociedad española, limitando el objeto material de la investigación a las instituciones de la Administración Central del Estado; al uso de las redes sociales con mayor extensión en nuestro país, Facebook y Twitter, por las instituciones que disponen de ellas. Un objeto abordado para conocer la audiencia producida por la actividad en redes sociales digitales por instituciones de la Administración Central; identificar la existencia de políticas públicas de comunicación concreta con respecto a estas redes; y establecer las principales dinámicas de la opinión pública en torno al uso que hacen las instituciones del estado de las mismas, así como la percepción de interactividad y participación de los ciudadanos a través de este canal de comunicación. ¿Se relacionan los ciudadanos con estas cuentas de manera igual o distinta a como se relacionan con otras cuentas en redes sociales online, incluyendo cuentas de otras instituciones? 


\section{Audiencias y social media desde la política}

Desde sus primeras apariciones, las redes sociales resaltaron como fuente específica productora de audiencias (Nightingale, 2011). Estudios vinculados con el marketing dan instrucciones para obtener más audiencia-consumidores a través de redes sociales, buena parte de ellos preocupados en segmentaciones de registros (Bartley y Child, 2014). Y desde fecha cercana a sus inicios, se ha venido destacando cómo cambia la relación entre instituciones políticas y ciudadanos (Bennett, 2012). Sobre el uso de redes sociales por instituciones públicas, convirtiéndose en emisores, destacan investigaciones centradas en instituciones únicas o en un nivel concreto de la Administración, como el volumen que compara las estrategias de social media en el nivel local de distintos puntos del mundo: Europa 0ccidental, China, Australia, etc. (Sobaci, 2016), o en un único país, Japón (Kaigo, 2017). No obstante, bien como apoyo o continuación de otros medios de comunicación, bien como conjunto mediático específico en sí mismos, observando cómo actúan los usuarios en las redes -sin centrarse en una cuenta de red social online particular-, pocas investigaciones focalizan los procesos de compartición de información y estrategia (Lee y Ma, 2012).

Asimismo, la consideración de ganancia en transparencia gubernamental ha situado a las redes sociales en el centro del análisis de este concepto politológico, hablando de una sociedad de la supertransparencia (Austin y Upton, 2016), y subrayando la dificultad de las organizaciones para mantener informaciones fuera del espacio público. Transparencia analizada también en sentido inverso, como la vulnerabilidad informativa de los ciudadanos hacia el poder (Trottier, 2012). Una relación ambivalente que arraiga en la complejidad de la matriz democratizacióntransparencia, pues contiene distintos procesos de democratización y de actuación que, a su vez, implica distintas concepciones de transparencia.

Más allá de esta función de transparencia o ampliación de la democracia por instituciones públicas (Callejo et al., 2017), este trabajo toma una perspectiva inversa, centrándose en la capacidad de las instituciones para conformar determinados estados de opinión en amplias capas de la sociedad, a través de un elevado número de seguidores en redes sociales. En la posibilidad de actuación conjunta de 
Una Aproximación integral a la presencia de las administraciones públicas en redes... | 211

ARTíCULOS DE INVESTIGACIÓN

una red articulada de cuentas de redes sociales, dependientes organizativamente de un único vértice jerárquico (Presidencia de Gobierno).

\section{Métodos}

El primer objetivo tiene un eminente carácter fáctico: observar lo que se hace diseñando una metodología de observación focalizada en registros que dejan las redes sociales digitales. Hemos transformado los registros, las huellas de lo que hacen los actores -instituciones públicas con cuenta en Twitter o Facebook-, en datos. El segundo y tercer objetivo aparecen vinculados con el sentido que se da al uso de estas redes por los ciudadanos, respecto a las cuentas de instituciones públicas. A partir de ahí, incorporar formas de aproximación empírica capaces de recoger el sentido dado por los distintos actores.

La actividad de Twitter y Facebook se registró a partir del seguimiento durante 61 días (31 enero al 1 abril, 2017), de las cuentas de instituciones de la Administración Central. Como el objeto es observar dicha actuación institucional y funcional, se ha dejado fuera la cuenta con mayor número de seguidores, la del Presidente, pues teniendo la máxima responsabilidad política y ejecutiva, no tiene atribuidas funciones sobre campos específicos de actuación. Se han seguido los mensajes de 57 cuentas de instituciones de la Administración Central en Facebook (captura con software Netvizz) y de 90 cuentas en Twitter (captura con sofware Ncapture, de NVivo), construyendo una muestra de la actividad en las redes sociales digitales de las instituciones de la Administración Central con cuenta: captura de 7.348 mensajes en Facebook y 39.359 en Twitter.

Para observar la concepción de sus respectivas audiencias, se han realizado cinco entrevistas cualitativas a responsables de cuentas institucionales. El principio estructural ha guiado la construcción de tan pequeña muestra, tratando que estuvieran presentes administradores de cuentas con muchos y pocos seguidores, de instituciones de diferente tamaño. ${ }^{3}$ La producción de discursos que nos aproximen al sentido que se da a la relación, por ciudadanos-audiencia, a mensajes emitidos por instituciones, se ha realizado a través de grupos de discusión entre usuarios de redes sociales. La opción por esta práctica de investigación se justifica por la 


\section{ARTÍCULOS DE INVESTIGACIÓN}

búsqueda de los marcos ideológicos de los usuarios, de manera que el acceso a su percepción de las cuentas de redes sociales digitales institucionales surgiera del discurso espontáneo, y no de la producción de una situación de pregunta, tendente a respuestas normativas o de deseabilidad social. La aproximación ha estado constituida por el material discursivo producido por tres grupos de discusión, con los siguientes perfiles (todos usuarios de Twitter o Facebook):

- Jóvenes (hombres y mujeres) (25-30 años) profesionales ocupados, en ocupaciones vinculadas con estudios realizados y no relacionadas con marketing, política, empleados públicos y similares. Clase social media-media/ media-alta (GD.1). ${ }^{4}$

- Hombres (30-40 años). 0cupados en sector servicio y administrativo, pero no como empleados públicos. Clase media (GD.2).

- Mujeres (30-40 años). La mitad ocupadas. Clase media-baja (GD.3).

La dinámica de las reuniones fue el uso habitual de las redes sociales digitales: motivaciones, resistencias, argumentos, etc.; actividades que han dejado de hacerse 0 se hacen menos, de manera que tal cambio pudiera atribuirse al mayor uso de las redes sociales, especialmente dirigido a sondear la menor relación con otros medios; cuentas no personales de redes sociales digitales que se siguen, razones; presentación de mensajes en redes sociales de instituciones de la propia Administración Central y en redes sociales de cuentas instituciones: empresas, instituciones públicas, organismos, etc.

El contexto de observación, eminentemente aplicado de la investigación, no impide señalar las hipótesis presentes: la de la relevante extensión cuantitativa de la audiencia en tales redes sociales, en primer lugar, $\mathrm{y}$, segundo, la de la inexistencia de estrategia. 
Una Aproximación integral a la presencia de las administraciones públicas en redes... | 213 ARTíCULOS DE INVESTIGACIÓN

\section{Resultados}

\subsection{Actividad y eco de la actividad en Twitter}

Los perfiles institucionales de Twitter observados suman 9.478.314 seguidores. Partiendo del número de seguidores que tienen las cuentas analizadas, se observa gran diferencia. Unas superan los dos millones y medio de seguidores (PN), otras apenas llegan al medio millar. La que cuenta con más seguidores tiene cinco mil veces más que la que cuenta con menos. Las inmensas diferencias en cuanto a la cantidad de audiencia acumulada parecen señalar directamente la inexistencia de una política general con respecto al uso de este instrumento que hacen las instituciones, desde la asunción de que los distintos resultados se deben a distintas estrategias de producción de seguidores.

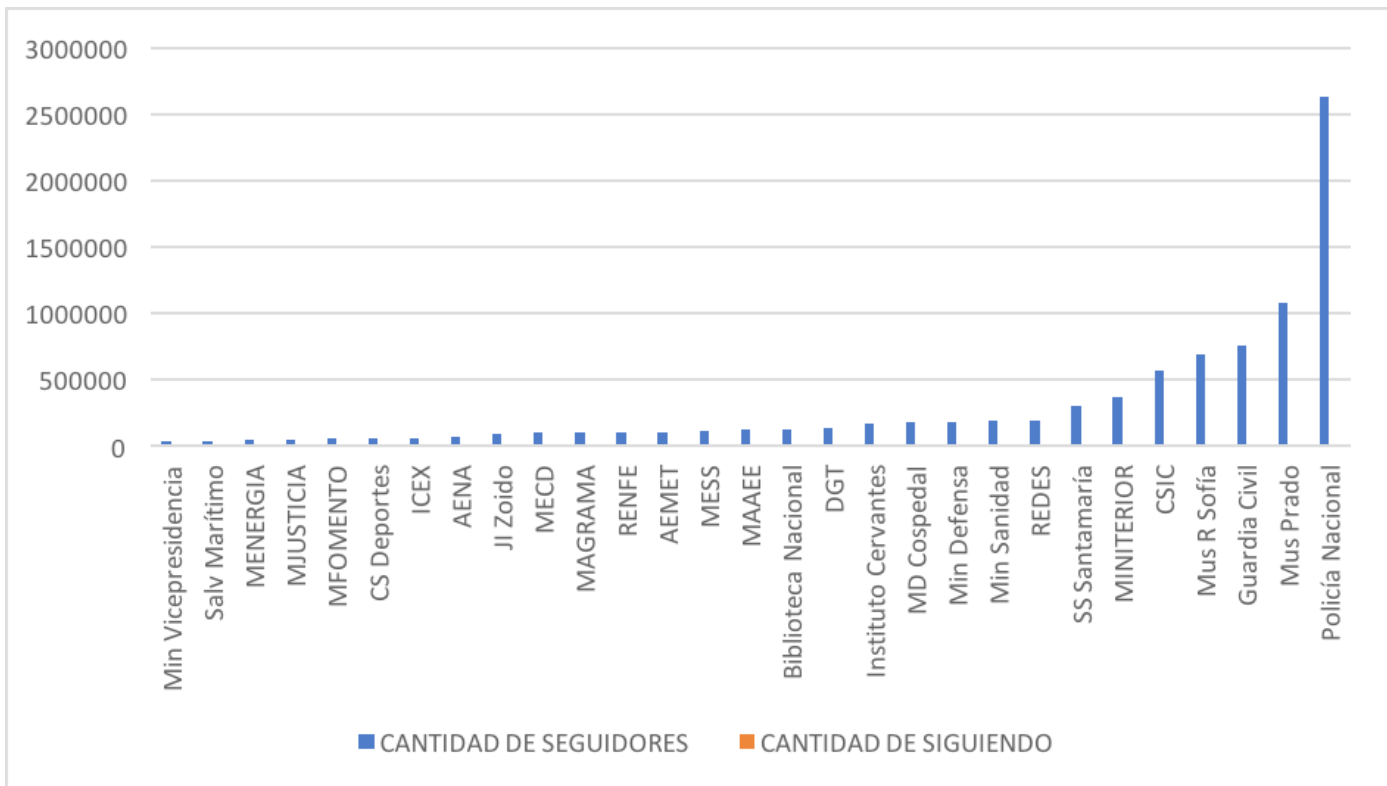

Gráfico 1: Número de seguidores cuentas Administración Central y cuentas seguidas en Twitter (las más seguidas).

Fuente: Elaboración propia 
Ha de destacarse cómo la acumulación de seguidores apenas tiene relación con una política de cierta reciprocidad, de seguimiento. La cuenta con más seguidores -2.639.230- en Twitter es la de la Policía Nacional. Sin embargo, no sigue a nadie. Continúan por número de seguidores la del Museo del Prado (1.080.945), la de la Guardia Civil (GC) (762.011) y la del Museo Reina Sofía (696.494). Sigue la del CSIC, con más de medio millón de seguidores. Resultados que invitan a preguntarse la relación que pudiera existir entre, por un lado, estas instituciones, o, por otro lado, su forma de actuar en las redes sociales. En principio, parecen presentarse dos tipos o categorías de instituciones. Es decir, especialmente aquellas relacionadas con la seguridad, como son Policía Nacional o Guardia Civil. Instituciones que, más allá de actuar sobre un campo común de la realidad social -la seguridad pública- se han caracterizado en nuestro país por una diferenciada gestión de las redes sociales. Sin embargo, el otro conjunto de instituciones parecen tener en común la asunción de una función divulgativa en su actuación en las redes sociales.

Como puede observarse en el gráfico 1, la relación entre número de seguidores de estos perfiles institucionales en Twitter y número de perfiles seguidos es muy desigual. De hecho, apenas puede apreciarse visualmente el monto de cuentas seguidas en cada uno de los casos. Esto parece apuntar a una estrategia comunicativa general de poca interactividad $\mathrm{y}$, sobre todo, al interés que prima a la hora de establecer los perfiles en cada una de las instituciones, de manera que se da una preferencia casi absoluta a la acumulación de audiencia para, así, hacer llegar los mensajes, que a la promoción o seguimiento de cuentas y, de esta manera, a la apertura a lo que dicen los ciudadanos.

La actividad observada en Twitter de las distintas cuentas observadas pertenecientes a organismos e instituciones de la Administración Central alcanza la gestión de 39.359 mensajes. Ello supone una media diaria de algo más de 7 mensajes por cuenta. RENFE, con un total de 3.705 tuits y retuits, es la cuenta con mayor actividad. Una media de 84,2 mensajes por día laborable. A continuación encontramos la Agencia Estatal de Meteorología (AEMET: 3.265mensajes) y la Biblioteca Nacional (BN) (2.739), con una actividad media en días laborables de 74,2 y 64,3 tuits 0 retuits. 
Una Aproximación integral a la presencia de las administraciones públicas en redes... | 215 ARTÍCULOS DE INVESTIGACIÓN

En principio, no existe una relación directa entre el total de seguidores y flujo de mensajes en la cuenta. Hay que llegar al sexto lugar por orden de actividad para encontrar a la GC (1.586 mensajes), con un buen número de seguidores. Es decir, no hay que realizar una intensa actividad en la cuenta, en forma de sucesiva y continua emisión de mensajes, para tener un número importante de seguidores. Es más, siguiendo en parte los argumentos establecidos más arriba, parece cuestión de la específica estrategia de comunicación, elaborando un particular tipo de mensaje muy vinculado a la vida cotidiana de los ciudadanos, y el tipo de institución, como cuando se hacía referencia a la función divulgativa asumida por algunas instituciones.

Sin embargo, los mensajes de las tres cuentas con mayor actividad tienden a un sentido diferente. Mientras que RENFE aúna mensajes informativos promocionales con reclamaciones en determinados puntos, AEMET incluye predicciones climáticas y seguimiento de fenómenos atmosféricos relevantes durante los días observados. En el análisis del perfil de la Agencia Meteorológica, cabe destacar la estrategia de promoción de la participación de los seguidores, especialmente a partir del envío de fotografías: envíos de fotos por ciudadanos recogiendo un "momento atmosférico" del día, donde la motivación artística -mandar una buena foto, algo que sea bonito- parece prevalecer, en la mayor parte de los casos observados, sobre la función referencial o informativa sobre el "estado del tiempo".

La BN combina información de agenda sobre acontecimientos y convocatorias en su sede, y presentación del patrimonio artístico que guarda. No obstante, buena parte de la acumulación de actividad deriva de la sucesión de mensajes a partir de un tema (escritor, músico, pintor, etc.) del que se celebra efeméride. En esta cuenta dominan mensajes divulgativos.

El eco de la actividad de las cuentas en Twitter de las instituciones de la Administración Central puede aproximarse a partir de los retuits que reciben sus mensajes. Tal eco no sólo recoge lo que podríamos asumir como el impacto de un mensaje, en función de las características de éste, sino también el número de seguidores, pues a mayor número es mayor la probabilidad de que un mensaje emitido sea retuiteado. 


\section{ARTÍCULOS DE INVESTIGACIÓN}

Las cuentas que obtienen, de media, mayor número de retuits por cada tuit emitido están relacionadas con el Ministerio del Interior. Seguramente tiene que ver con el seguimiento de una estrategia común. Al menos, con la asunción explícita o implícita de un patrón común de actuación en redes sociales online. La GC (327,51 retuits de media por tuit original emitido), es la que mayor eco encuentra a sus mensajes. Sigue la PN (276,87retuits de media). A bastante distancia, las cuentas del Ministro de Interior $(102,6)$, la Ministra de Defensa $(96,54)$ y el Ministerio del Interior $(91,77)$.

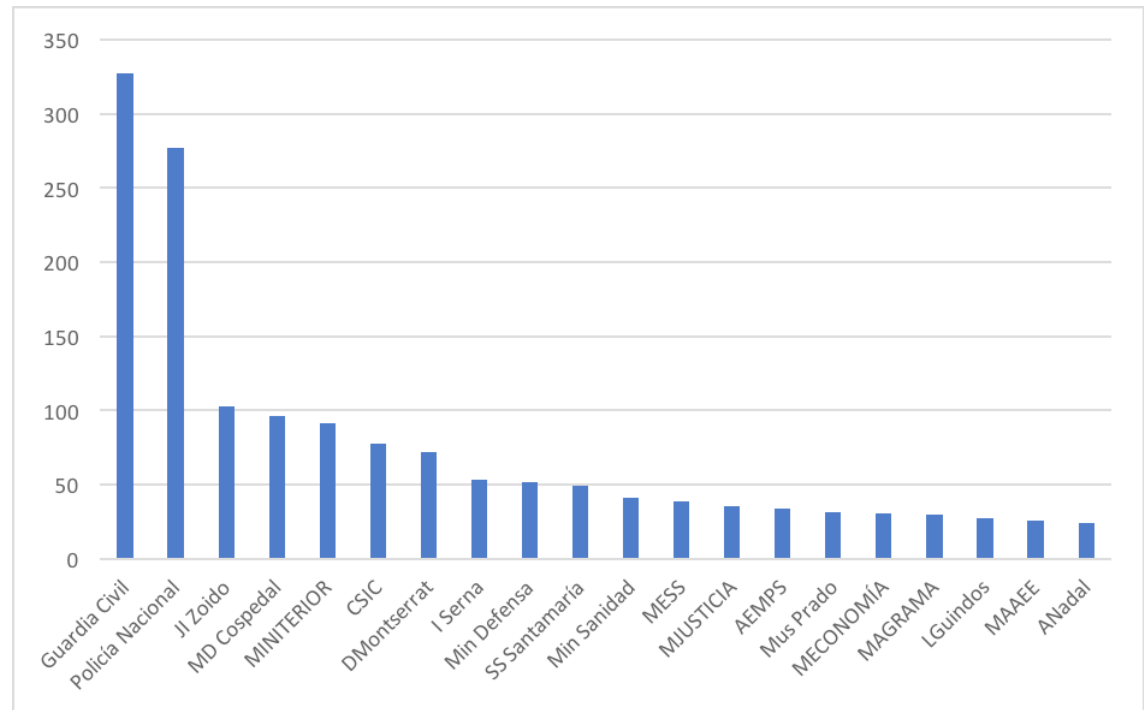

Gráfico 2: Media de retuits obtenidos de tuits originales (20 con medias más altas).

Fuente: Elaboración propia

\subsection{Actividad y eco de la actividad en Facebook}

En cuanto a la otra red social, Facebook, se han analizado 57 cuentas de organismos e instituciones de la Administración Central, con un total de 7.348 mensajes. La media de mensajes gestionados por día apenas llega a dos. El número total de seguidores acumulados por estas cuentas es de 3.589.803. La cuenta del Museo del Prado, con casi novecientos mil seguidores, presenta el mayor número de fans, por delante de la cuenta de la PN, con poco más de medio millón de seguidores. El mayor papel de las imágenes en Facebook parece estar relacionado con el 
Una Aproximación integral a la presencia de las administraciones públicas en redes... | 217 ARTÍCULOS DE INVESTIGACIÓN

ascenso al primer puesto de la cuenta de la pinacoteca: una institución en la que una de sus funciones principales es gestionar imágenes, parece más afín a esta red social, en la medida que es concebida para gestionar el uso de imágenes, junto a Instagram, tal como refieren los usuarios en los grupos de discusión. La tercera cuenta en seguidores es también un museo, el Reina Sofía, con cerca de trescientos cincuenta mil; y la cuarta también hace amplio uso de imágenes, es la de la BN.

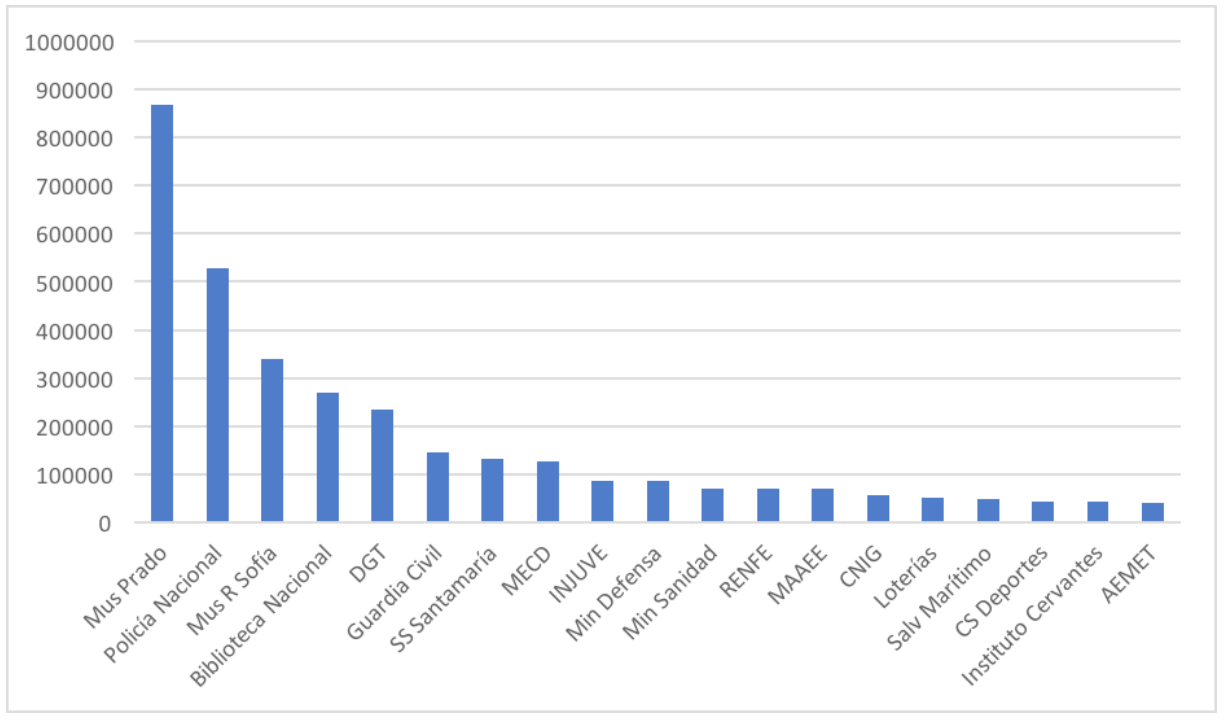

Gráfico 3: Número de seguidores en FB de las cuentas de las instituciones de la Administración Central (20 más seguidas).

Fuente: Elaboración propia

Al igual que ocurría en Twitter, vuelven a observarse diferencias relevantes en cuanto a la audiencia acumulada por los distintos perfiles institucionales. También puede observarse que son prácticamente los mismos perfiles institucionales que encabezan el ranking en Twitter los que están en Facebook. Resultado que no parece explicarse por la casualidad. En cuanto a los mensajes, la cuenta con más flujo de mensajes es la del CSD (658, en forma de link, la mayoría). Esta cuenta trae a la suya mensajes de deportistas, federaciones o acontecimientos, convirtiéndose en una especie de tablón donde se inserta los mensajes que produce el deporte español. 
Sigue la cuenta de RENFE (463 mensajes), donde dominan mensajes de texto, tanto en clave de preguntas, como de respuestas por la institución, no faltando quejas o comentarios procedentes de un distanciamiento de la institución.

En la tercera cuenta por flujo de mensajes, la del Ministro de Interior, prácticamente la mitad de los mensajes constituyen fotos. Agrupando las tres cuentas con más flujo, se observa una estructura muy desigual. El tamaño de los distintos flujos parece depender de la existencia, en cada una de las instituciones, de una estrategia comunicativa, que tal vez no sea compartida, pero que, en cada caso, parece regida por un horizonte de cómo se concibe la relación con los ciudadanos, $\mathrm{y}$, por lo tanto, con las respectivas audiencias o conjunto de seguidores. Con las debidas precauciones, podría decirse que cuando la relación se establece como portavoz de los mensajes que se dan en un campo, adquiere la forma tomada en la cuenta del CSD, con aspecto de "tablón" gestionando. Caso parecido es el de INJUVE (373 mensajes), o Loterías (347). Cuando se trata de una relación de información sobre el servicio de la institución, se configura la estructura de flujo como en la cuenta RENFE. Cuando la relación tiene componente expositivo-descriptivo, pasando por exposición de imágenes, la estructura es la que presenta la cuenta del Ministro del Interior, semejante a las de AEMET, Ministerio de Educación y Deportes o, especialmente, Museo Reina Sofía y Salvamento Marítimo.

Interesa destacar la relación entre mensajes propios, emitidos por la propia institución, y mensajes ajenos, dentro del flujo observado en las cuentas de Facebook. Mientras el flujo nos ofrece la actividad en la cuenta, los mensajes propios indican la actividad de la institución en la red. Si desde la perspectiva comunicativa puede ser interesante el total del flujo, con importante peso de mensajes ajenos que indicaría como la cuenta se convierte en ventana de la institución al exterior; desde la perspectiva de seguir una política comunicativa concreta, hay que valorar la actividad emisora.

Así, la cuenta del CSD presenta una relación de casi del doble de mensajes propios (533) frente a mensajes ajenos (233). Sin embargo, en RENFE hay casi diez veces más (416) mensajes ajenos que propios (44). Según el total del flujo, se observa cierto equilibrio entre mensajes propios (217) y ajenos (188), en la del Ministro de Interior. 
El modelo mayoritario está dirigido por un dominio de los mensajes propios sobre ajenos, donde el control y gestión del flujo se realiza desde la propia cuenta analizada. Si atendemos a las características del conjunto de mensajes, en cuentas donde dominan mensajes propios, se trata, fundamentalmente, de inserción de links que conectan con cuentas o espacios ajenos a la propia. Esta mayor actividad parece focalizada en una conducción y redifusión del tráfico informativo existente en un campo, más que en la emisión de contenidos propios. Así es para las cuentas del CSD y del INJUVE.

Por otro lado, se observa cierto equilibrio en cuentas (Ministro Interior, AEMET) donde los mensajes en forma de foto/vídeo cobran especial relevancia, comparado con otras. También en este caso hay excepciones. En las cuentas del Ministerio de Educación, Cultura y Deporte y del Museo Reina Sofía, aun cuando son netamente mayoritarios los mensajes propios, hay una proporción relevante de fotografías. Parecen, por lo tanto, cuentas centradas en el intercambio de fotografías en la red. Acentuado con las características de los mensajes propios, donde las del Ministro de Interior y AEMET están especialmente dominadas por fotografías y vídeos, y su emisión se centra en este tipo de mensajes.

Las cuentas del CSD, Loterías e INJUVE están casi exclusivamente dominadas por links. Ello nos aproxima a la conclusión de que las cuentas de Facebook que presentan mayor actividad propia son aquellas que más centran sus mensajes en la publicación de links, en la mayor parte de las ocasiones referidos a actividades, acontecimientos $\mathrm{y}$, en general, agendas de sus campos de actuación.

De manera semejante a como se ha hecho con la relación mensajes propios/ajenos, respecto a los tipos de mensajes propios, como una mayor aproximación a lo que cada institución hace en su cuenta de Facebook, nos encontramos con cuentas en las que son ampliamente mayoritarios los links y cuentas que lo son las imágenes. Más allá de esta división, el caso del Ministerio de Hacienda, con una actividad media, está dominada por mensajes propios.

Por su potencial relevancia para políticas de transparencia en redes sociales digitales, destaca otra cuenta en cuya emisión es relevante el peso de los mensajes 
de texto, la del Ministerio de Educación, Cultura y Deporte, además del ya mencionado Ministerio de Hacienda. Por último, apuntar la casi inexistencia de mensajes musicales, con la excepción del Reina Sofía.

A partir del software utilizado (Netvizz) para la recolección y análisis, puede realizarse una aproximación a la recepción de los mensajes emitidos por las instituciones de la Administración Central desde sus cuentas de Facebook. Obteniendo así un acercamiento al eco que tiene la actividad en la red social online de tales instituciones. El análisis del eco está mediado por el número de seguidores o fans que tenga. De hecho, una cuenta tiene mayor probabilidad de recibir un mayor número de feedbacks, si dispone de un número importante de receptores de los mensajes originales susceptibles de generar reacción. Señalar la relativa plausibilidad del supuesto retroactivo inverso. Podría establecerse que el número de seguidores de una cuenta está relacionado con una actividad acumulada, que ha ido obteniendo una respuesta positiva de los receptores.

La cuenta que recibe una media elevada de "me gusta" ("likes") por mensaje emitido es la del Museo de Prado (2.513,66likes). Le sigue la cuenta de la PN (2.224,53 likes). Esta segunda cuenta no se encontraba entre las de mayor actividad -con mayor número de mensajes emitidos propios durante el período analizado-, sin embargo, los pocos mensajes que emite tienen un notorio eco. Algo parecido podría decirse de la cuenta de la GC, con una media de 1.661,02 likes por mensaje emitido, ocupando la tercera posición. Una tónica de éxito en la recepción media sin una extensa actividad que sigue en las cuentas de la Vicepresidenta del Gobierno y el Ministerio de Defensa.

Solamente cinco -Museo del Prado, BN, Salvamento Marítimo, DGT y Museo Reina Sofía- tienen una media de likes por mensaje por encima de la media presentada por el total de cuentas analizadas (168,83 likes de media en el total), están entre las que mayor actividad propia presentan; y una -Museo Prado- entre las de mayor media.

¿Hasta qué punto cabe asumir establecida una relación entre baja actividad en la red social digital y éxito de los mensajes? A ello apuntan los datos registrados 
y analizados; pero hay que ser prudentes en la explicación, pues tal éxito podría deberse a distintos aspectos de la relación entre perfiles -institucionales y ciudadanos- en las redes sociales. Algunas manifestaciones de los grupos de discusión han apuntado cierto rechazo al verse como continuos receptores de mensajes institucionales o corporativos. La proliferación de mensajes no parece ayudar a fortalecer la vinculación entre instituciones y ciudadanos.

El resultado de ordenar las cuentas por el número medio de otro tipo de respuestas (comentarios, emoticonos o similar, compartir) es bastante semejante. Algo que hace considerar que el eco de los mensajes en las redes sociales es general, siendo secundario el que se trate de un eco, dentro de las propias redes sociales, en forma de mensaje de like, comentario, emoticón o, simplemente, compartiendo el original con otras cuentas.

La cuenta de la PN registra una media con mayor número de respuestas -distintas a los likes- con un total de 4.581,48 respuestas. Sigue la del Museo del Prado (3.716,96 respuestas) y la de la GC (2.810,93 respuestas). Estas tres cuentas, por este orden, presentaban mayor número de seguidores en Facebook, lo que nos sitúa de nuevo en la estrecha relación entre número de seguidores y eco de los mensajes.

En las formas de recepción activa a los mensajes propios, con registro de algún comportamiento de respuesta, además de los likes, cabe destacar extenso uso de emoticonos o signos icónicos destinados a representar la reacción anímicoemocional producida en los receptores ante esos mensajes originales. Con mayor pertinencia que en otros tipos de respuesta, cabe hablar de mensajes de reacción.

La mayoría de los mensajes de reacción registrados son de aprobación (like/ gusta) o de notable aprobación (love/gusta mucho). Sólo algunos son de risa (categoría "ha,ha" del programa utilizado) y algunos pocos más de tristeza ("sad") o enfado ("angry"), tal como aparecen en las reacciones a mensajes emitidos por las cuentas de PN o GC, principalmente. No representan desaprobaciones a los mensajes en sí mismos, sino distanciamiento o reacción a la referencia de los mensajes con un sentido condenatorio por los emisores, como es el caso de la mayor parte de los mensajes que han recibido tales reacciones. Ejemplos que ilustran esta situa- 
ción son relativos a violencia de género o maltrato de animales. El propio emisor condena los actos referidos y las reacciones son de enfado/tristeza por el acto, no por el mensaje en sí, menos aún, con respecto a la institución.

Estas formas de participación emocional en los contenidos de mensajes emitidos por instituciones de la Administración Central en sus cuentas de Facebook pueden ser tomados como indicadores de proximidad entre ciudadanos e instituciones a partir de un lenguaje -con símbolos- de uso frecuente en estos medios. Proximidad que señala la proyección emocional de las instituciones cuando utilizan estos medios de comunicación. A través de la condena de un hecho por la institución, se proyecta emoción. Se trata de mensajes expresivos, en los que la institución toma posición, transformándose en sujeto de la enunciación. Ahora bien, por su fuerte contenido emocional, llaman a la implicación, pues interpelan al receptor solicitando complicidad, e incluso identificación, en contra de este tipo de hechos aun cuando sea por omisión. Las características del mensaje conllevan cierta exigencia de implicación y, por lo tanto, de demanda de respuestas por el receptor.

\subsection{La recepción}

Las redes sociales online están incorporadas a la vida cotidiana y, sobre todo, se usan. Aunque no todos los ciudadanos son usuarios y cabe establecer niveles de uso entre los que sí lo son. No es objeto de este artículo y extendería su extensión, pero ha de tenerse en cuenta la experiencia de uso general en las redes como marco para establecer el tipo de recepción de mensajes desde las cuentas en social media de las instituciones de la Administración Central, así como para la relación que establecen los ciudadanos con ellas.

Dado que suele tratarse de instituciones conocidas, no parece que la desconfianza procediera del desconocimiento. Sin embargo, el contexto de duda, temores y sensación de vulnerabilidad e incertidumbre rodea su uso y, por tanto, la relación con quien se encuentre en ellas. Contexto de desconfianza en el uso de los social media acentuado cuando se trata de cuentas de instituciones. La interacción queda limitada, fijando la relación en un flujo unidireccional de información. De hecho, como se pone de relevancia en el grupo 2, no se quiere interactuar, buscándose solo 
Una Aproximación integral a la presencia de las administraciones públicas en redes... | 223 ARTÍCULOS DE INVESTIGACIÓN

la información, haciendo referencia a un ideal de mensaje capaz de solo contener información. Como apuntan más adelante: Yo lo utilizo sobre todo para información, y rapidez, rapidez, rapidez, rapidez (GD.2)

Rapidez de información de primera mano y específica:

- No, este le veo bien, este le veo bien. Es una forma, es formación, es algo que te puede venir bien en un futuro (GD.2)

- Claro, pero por eso te digo, que a lo mejor si no buscas algo concreto de, pues voy a ver si Hacienda da subvenciones (GD.3)

Las instituciones se convierten en fuentes rápidas de información, debido a que ni las mismas, ni su audiencia, requieren intermediación. Esto explica la valoración de la información; pero no la expresada escasa inclinación a la interacción, cuando parecía ser éste el valor añadido de los social media. Fuentes rápidas y reconocidas en su especialización:

- Moderador: ¿Y la Policía Nacional, qué te dice?

- M3: Te cuentan cosas.

- M5: Pues bulos que haya o engaños o estafas que se están llevando a cabo o...(GD.3).

Desde los grupos de discusión, las instituciones son las instituciones. Esto es, a la vez, fuente de confianza y cierta desconfianza. Confianza en el reconocimiento, de saber con bastante seguridad qué es cada institución. No hay problemas de identificación de la fuente, de "perfiles falsos". Desde este punto de vista, la cuenta de la institución es la institución, con su fuerza simbólica y estabilidad. Están validadas de antemano.

- M1: Y ahí te da como un poco más confianza porque sabes que si alguien se pone un perfil diciendo que es la Policía y no lo es, el marrón es más grande que si... 


\section{ARTÍCULOS DE INVESTIGACIÓN}

- H2: No, pero luego está el tic este que ponen, de, de reconocimiento.

- H1: Sí, como que está validado y tal.

- H2: 0 sea, que no es un perfil falso. (GD.1).

La confianza en el reconocimiento se ve compensada con desconfianza en las consecuencias del seguimiento de esa institución, el grado cero de la interacción, $\mathrm{y}$, en mayor medida, la desconfianza sobre las consecuencias de emitir mensajes críticos con respecto a la institución. Es una cuestión de percepción de relación asimétrica. Claro está, cuando el contacto se limita a recibir información de servicio (transporte, meteorológico, etc.), la desconfianza es mínima, casi inexistente. Sin embargo, en casi toda relación con instituciones públicas en redes sociales online se percibe estar dando información y estar siendo controlado por el poder del Estado, que tiene dibujado, desde la perspectiva de los usuarios, como centro de control el Ministerio de Hacienda (denominado "Hacienda"). Todas las instituciones públicas son un poco Hacienda, como si estuviera Hacienda detrás:

Moderador: Sí, pero una cosa es internet, sí, pero digo el, digo las redes sociales, el tenerle como..., no sé si como..., si se dice así, como amigo, ¿se tiene como amigo a la oficina de empleo?

- H3: No, gracias. Como amigo, no.

- H1: Es seguir.

- H6: Es seguir, seguir, gracias, seguir. Como amigo, nunca, jamás [risas].

- H1: Señor Montoro no [risas].

- H3: Amigos no, amigos no vamos a ser jamás.

- H1: Eh, no [risas]. (GD.3) 
Si la motivación de los individuos para entrar en contacto con las instituciones públicas en las redes sociales online está centrada en la recepción de información, el dibujo de la motivación de las instituciones públicas parece débil. Es más, en la medida que se señala la obligación como fundamental razón para que las instituciones públicas tengan cuenta de redes sociales online ("no pueden no estar" GD.3), la motivación surgida de las instituciones es escasa.

\section{Conclusiones y discusión}

La audiencia acumulada por las instituciones de la Administración Central en las redes sociales supera los trece millones de seguidores (TW+FB: 9478314+3589803=13.068.117). Teniendo en cuenta duplicaciones, se aplica un corrector (el 16\% de la población mayor de 18 años comparte Twitter y Facebook, porcentaje que asciende al $24 \%$ de los que tienen $\mathrm{Tw}$ o $\mathrm{Fb}$, que no quiere decir que tengan las mismas cuentas en las dos redes sociales): $13068117 \times 0,76=9.931 .769$ seguidores netos. Una cantidad superior a la de la mayor parte de los medios de comunicación en español, aunque su producción de contenidos sea más limitada, lo que no impide que se convierta en un importante potencial de receptores de un único mensaje.

El tamaño de la audiencia de cada institución, en su respectiva cuenta, aparece condicionado por la articulación de, al menos, cinco factores:

1. La relevancia de la institución: hay instituciones que se consideran muy relevantes para la vida cotidiana y práctica de los sujetos (PN, GC, RenfeCercanías).

2. La relación ciudadana con esa institución: desde la proximidad y apoyo (PN, GC) a la subordinación o acentuación de la sensación de ser vigilado por la Administración Pública (Webster, 2012; Trottier, 2012), que, en nuestra investigación se ha concretado en la imagen de Hacienda. Si tal relación de confianza/desconfianza puede extenderse al conjunto de cuentas de las instituciones observadas, es mayor con respecto a unas instituciones que con respecto a otras. Se trata de relaciones que se perciben particularizadas, que 
no reflejan la relación con el conjunto de la Administración Central, sino con la institución específica.

3. La integración de la política comunicativa de los organismos a través de redes sociales, de manera que se constituye un estilo propio de emisión, que lleva a determinadas expectativas de recepción (GC, PN).

4. La integración de los contenidos en la vida cotidiana y gustos de los receptores (CSD, BN, Museo del Prado).

5. La interactividad entre organismos y ciudadanos en las redes sociales. Factor que tiende a ocupar un lugar secundario, relevante en algunas cuentas (CSD).

Estos factores han derivados principalmente del análisis e interpretación de la relación de cantidad de seguidores con los resultados del seguimiento de lo que hacen las distintas cuentas, así como la explicación de lo que hacen distintos tipos de cuentas de las instituciones analizadas, de sus estrategias -a través de las entrevistas en profundidad- y del discurso de los grupos de discusión, donde se han recogido las expectativas de los ciudadanos con respecto a estas cuentas institucionales.

Ahondando en la interpretación de los discursos producidos por los receptores, se recoge un escaso sentimiento de democracia (Ceron, 2017), en la relación con las cuentas de social media de instituciones. Al menos desde el discurso espontáneo, no se establece una relación entre uso institucional de los social media y democracia. Ello, a pesar de que se podría interpretar la exigencia de disposición de este canal de comunicación -“tienen que estar"- como una exigencia democrática. Sin embargo, no podría decirse que los ciudadanos se relacionan con ellas desde un sentimiento de democracia. Domina la racionalización -rapidez de información, estar al tanto- sobre los sentimientos al explicar por qué se sigue este tipo de cuentas. 
Los nuevos canales de comunicación en general y las redes sociales online en particular se han venido refiriendo como base de otra forma de relación entre sociedad y Estado, con auge de dimensiones como transparencia o participación (Austin y Upton, 2016). Pero ni el comportamiento observado en los distintos perfiles de las instituciones, ni las demandas sobre tal comportamiento registradas en nuestros grupos de discusión parecen dirigirse por tales caminos. Se apunta un distinto tipo de relación, menos mediatizado e incluso en alguna medida menos distante entre ciudadanos y Estado; pero no más transparente -las suspicacias se mantienen entre la ciudadanía- ni más participativo, quedando la interacción en un comportamiento que roza lo marginal.

Ha de resaltarse que las capacidades y formas de actuación de las distintas cuentas de instituciones de la Administración Central en redes sociales distan de ser homogéneas. Se concreta esa amalgama de actuaciones en tal esfera pública, tanto en las características y estilo de los mensajes, como en amplitud de su alcance, en términos de seguidores de las respectivas cuentas.

En cuanto a los receptores, la principal motivación argumentada para constituirse en seguidor de las cuentas de redes sociales de las instituciones es como directos receptores de la información producida, sin intermediarios. Una relación que incluye el derecho a la información como parte de la concepción de ciudadanía. Una relación que, en todo caso, no parece establecerse sobre la cantidad o calidad de tal información sino que, con carácter ambivalente, se plantea sobre el eje confianza/desconfianza. Confianza por ser información directa. Desconfianza por la observación -y potencial registro- que la propia institución realiza sobre los mensajes que pueden generarse.

La recuperación de la perspectiva institucional en el análisis de redes sociales -instituciones con capacidad estratégica en la gestión de mensajes que circulan por sus canales- nos lleva a proyectar nuestra reflexión sobre el estado actual de la investigación de audiencias, preocupada en cómo integrar entre sus objetos de estudio los social media y sobre la amplia labilidad que toma el concepto de audiencia. 
Los social media son parte del sistema de comunicación mediada, ya sea relación convergente o en oposición con respecto a los medios de comunicación institucionales-tradicionales. Como hemos visto, los ciudadanos se informan de la realidad $\mathrm{y}$, sobre todo, de fragmentos especializados de la realidad - $\mathrm{y}$, en cierta medida, responden a esa realidad- a través del seguimiento de cuentas institucionales en las redes sociales online. Es decir, las utilizan preferentemente más como una fuente de información, que como un instrumento para la interacción o la participación. Ahora bien, admitirlas en el sistema de comunicación mediada significa, además de estar abiertos a la potencial oposición con respecto a los otros medios más conocidos, admitir el aumento en el margen de operatividad de otros agentes, lo que incluye tanto las audiencias, como a lo que antes quedaban relegados exclusivamente al papel de anunciantes o actores de la noticia, según la propia construcción que hacían los medios de comunicación. Tanto unos como otros, tal vez con flujos de desconfianza mutuos en la actualidad, pueden acceder directamente a la esfera pública, participar directamente en el sistema de comunicación mediada.

La respuesta a esa demanda de "información sin intermediarios", que parece dominar la relación que tienen los ciudadanos con los perfiles en redes sociales de las instituciones observadas, puede lograrse de muy distintas formas $\mathrm{y}$, sobre todo, desde muy distintas estrategias de comunicación institucional. La estrategia que ha tenido mayor éxito, según nuestro análisis, es la que rompe el efecto de "intermediación" a través de un lenguaje que intenta acercarse a la vida cotidiana de la audiencia, que busca reducir distancias entre institución y ciudadano, en sus propias formas de habla. De hecho, junto al lenguaje difusor-divulgativo observado en algunas instituciones (museos, Biblioteca Nacional), se han mostrado como prácticamente las únicas estrategias comunicativas existentes en estos canales por parte del conjunto de instituciones de la Administración Central observadas. La mayor parte de las instituciones parece que se limitan simplemente a estar "ahí", como nos señalaba en la entrevista una de las responsables de gestionar un perfil institucional. 


\section{Referencias bibligráficas}

Anduiza, E., Cantijoch, M., Colombo, C., Gallego, A. y Salcedo, J. (2010). Los usos políticos de internet en España. Revista Española de Investigaciones Sociológicas, 129, 133-146.

Austin, R.D. y Upton, D.M. (2016). Leading in the Age of Super-Transparency. MIT Sloan Management Review, 57(2), 25-34.

Bartley, T. y Child, C. (2014). Shaming the Corporation: The Social Production of Targets and the Anti-Sweatshop Movement. American Sociological Review, 79(4). doi:https://doi.org/10.1177/0003122414540653

Bekkers, V., Edwards, A. y Kool, D. (2013). Social media monitoring: Responsive governance in the shadow of surveillance?. Government Information Quarterly, 30(4), 335-342.

Bennet, W.L. (2012). The Personalization of Politics: Political Identity, Social Media, and Changing Patterns of Participation. AAPSS, 644(1). doi: https:// doi.org/10.1177/0002716212451428

Bernstein, M.S., Eytan Bakshy, M.B. y Karrer, B. (2013). Quantifying the invisible audience in social networks. En Proceedings of hte SIGCHI Conference on Human Factors in Compuitng Systems. doi:10.1145/2470654.2470658

Boczkowki, P.J. y Papacharissi, Z. (2018). Trump and the Media. Cambridge (Mass.): MIT Press.

Callejo, J., Agudo, Y., Illera, J. y Gutiérrez, J. (2017). Transparencia y redes sociales. Madrid: Dado.

Ceron, A. (2015). Internet, news, and political trust: The difference between social media and online media outlets. Journal of Mediate-Computer Communication, 20(5), 487-503.

García-Perdomo, V., Salaverría, R., Kilgo, D.K. y Harlow, S. (2017). The influence of news values and topics on popular social media content in the United States, Brazil, and Argentina. Journalism Studies. doi: 10.1080/1461670X.2016.1265896 Hansen, L.K., Arvidsson, A., Nielsen, F.A., Colleoni, E. y Etter, M. (2011). Good friends, bad news-affect and virality in twitter. Futue Information. doi: https://arxiv.org/pdf/1101.0510v1.pdf

Hayes, A.S. (ed.) (2018). Communication in the Age of Trump. Nueva York: Peter Lang. Lee, Chei Sian y Ma, Long. (2012). News sharing in social media: The effect of gratifications and prior experience. Computers in Human Behavior, 28(2), 331-339. 
Nightingale, V. (2011). Search and social media. En Nightingale, V.(ed.): The Handbook of Media Audience. 0xford: Willey-Blacwell, pp.86-109.

Rudat, A., Buder, J. y Hesse, F.W. (2014). Audience design in Twitter: Retweeting behavior between informational value and followers' interests. Computers in Human Behavior, 35, 132-139.

Rudat, A. y Buder, J. (2015). Making retweeting social: The influence of content and context information on sharing news in Twitter. Computers in Human Behavior, 46, 75-84.

Susskind, J. (2018): Future Politics: Living Together in a World of Transformed Tech. 0xford: 0xford University Press.

Trottier, D. (2012): Social Media As Surveillance. Farngam: Ashgate.

Webster, C. y William, R. (2012). Public administration as surveillance. En Ball, K., Haggerty, K.D y Lyon, D.(eds.): Routledge Handbook of Surveillance Studies. Londres y Nueva York: Routledge, pp.313-320.

\section{Notas}

[1] Investigación que sustenta esta publicación: Social Media e Instituciones Gubernamentales: el Uso de la Transparencia (SMIGUT), Ayudas de Acciones de Promoción de la Transparencia y Acceso a la Información Pública, 2016, J. Callejo (IP), J. Gutiérrez, Y. Agudo y J. Illera.

[2] Como referente de todos, Lasswell (1938). Herbert A. Simon, que pasa por ser el fundador (Celis, 2018) de la economía de la atención, en Simon (1996), asistió a las clases de Lasswell en Chicago.

[3] Se ha entrevistado a gestores de cuentas de institución pequeña con pocos seguidores, gestor de cuentas de institución grande con muchos seguidores, gestores de cuentas de instituciones grandes (Ministerios) con un número de seguidores alto y medio, y gestor de cuentas de institución grande, con pocos seguidores. Por razones de confidencialidad, no se exponen nombres de gestores, ni de instituciones.

[4] Referencia fragmentos discursivos: GD.1 (grupo de discusión 1), GD.2 (grupo de discusión 2) y GD.3 (grupo de discusión 3).

\section{(c) (7) (8)}

Esta obra está bajo una licencia de Creative Commons Reconocimiento-NoComercial 4.0 Internacional. 